\title{
Effects of Oxygen Supplementation on Acute Mountain Sickness Symptoms and Functional Capacity During a 2-Kilometer Walk Test on Chajnantor Plateau (5050 Meters, Northern Chile)
}

Juan A. Silva-Urra, BM, BSc; Constanza Urizar, BM; Carla Basualto-Alarcón, BM; Joan Ramon Torrella, PhD; Teresa Pagés, PhD; Claus Behn, MD; Ginés Viscor, PhD

From the Unidad de Fisiología, Departamento Biomédico, Facultad de Ciencias de la Salud, Universidad de Antofagasta, Antofagasta, Chile (Drs Silva-Urra and Urizar); Laboratorio de Ambientes Extremos, (ICBM), Facultad de Medicina, Universidad de Chile, Santiago, Chile (Drs Basualto-Alarcón and Behn); Departament de Fisiologia i Immunologia, Facultat de Biologia, Universitat de Barcelona, Barcelona, Spain (Drs Torrella, Pagés, and Viscor).

Objective.-The aim of this study was to test the hypothesis that administration of low-flow oxygen will improve physical performance in subjects unacclimatized to altitude. We evaluated the effects of oxygen supplementation on functional capacity and acute mountain sickness (AMS) symptoms in young, healthy male and female subjects who performed a 2-km fast walk test following rapid ascent to the Chajnantor plateau (5050 $\mathrm{m}$ above sea level) in Northern Chile.

Methods.-The participants were randomly distributed into 2 groups according to oxygen supplementation levels: 1 or $3 \mathrm{~L} \mathrm{O}_{2} \cdot \mathrm{min}^{-1}$. Within each group, males and females were evaluated separately. A preliminary walk test was carried out at sea level on a 100-m long, flat track with 10 U-turns. For the first walk at altitude, subjects carried the supplementary oxygen system but did not breathe the oxygen. Subjects received oxygen through a facemask the following day during the second test. The nights prior to altitude tests were spent at $2400 \mathrm{~m}$ in San Pedro de Atacama.

Results.-Supplementary oxygen administration during a $2-\mathrm{km}$ walk test significantly improved walking times at $5050 \mathrm{~m}$. We also observed a significant improvement in AMS symptoms. As expected, however, performance was poorer at altitude compared to test values at sea level, despite supplementary oxygen administration.

Conclusions.-Our findings demonstrate the beneficial effects of supplementary oxygen administration on physical capacity, reducing the incidence of AMS and, thus, improving health and safety conditions for high altitude workers following rapid ascent, when adequate acclimatization is not possible.

Key words: altitude work, acute mountain sickness, supplementary oxygen, 2-km walk test, Chajnantor plateau

\section{Introduction}

Several groups of workers, including researchers at astronomical observatories and miners or railway workers in the Andes and Central Asia, are routinely required to undergo a fast ascent from lowland levels to moderate and even high altitudes. Although some individuals show

Corresponding author: Gines Viscor, PhD, Universitat de Barcelona, Departament de Fisiologia i Immunologia, Av. Diagonal, 645, E-08071 Barcelona, Spain (e-mail: gviscor@ub.edu). a good response to sudden altitude exposure, others do not, and they experience different degrees of acute mountain sickness (AMS). The symptoms characterizing AMS can be assessed using the Lake Louise AMS score. ${ }^{1}$ Depending on intensity, AMS symptoms can produce a marked reduction in the capacity to carry out daily activities such as walking or completing work tasks. ${ }^{2}$ Many workers live at low altitude or sea level, and may carry out a wide range of activities before hypoxia occurs, depending on their work schedule. 
The Atacama Large Millimeter/Submillimeter Arrays (ALMA) project was launched by an international consortium in 2003. The observatory is situated on the Chajnantor plateau $(5050 \mathrm{~m})$ in the Antofagasta region, and has a permanent base camp at $2900 \mathrm{~m}$ that provides residential and leisure facilities for all personnel, including ALMA project employees and employees from contracting companies. The site hosts a variety of engineers, scientists, journalists, and other visitors, resulting in a heterogeneous population characterized by wide variations in age, health status, and physical condition. Both personnel and visitors are required to withstand very harsh environmental conditions, including high altitude, temperatures below $0^{\circ} \mathrm{C}$, wind speeds that are normally between 40 to $50 \mathrm{~km}$ per hour, and elevated thermal radiation. ${ }^{3}$ These harsh environmental conditions constitute a significant cause of delays in the work schedule as compared to similar tasks at lower altitudes. In addition, companies encounter great difficulties in retaining specialized personnel, who leave because of altitude intolerance. Furthermore, the incidence of vehicle accidents (especially vehicles overturning during descent) may be exacerbated by hypoxia, which can diminish sensorial perception, mental concentration, and speed of reaction, all implying a reduced ability to function.

It is well known that working conditions for commuters to high altitude can be improved significantly by oxygen enrichment of room air, ${ }^{4}$ especially at altitudes such as those on the Chajnantor plateau $(5050 \mathrm{~m}) .{ }^{5}$ However, most of the current tasks at the Chajnantor site are performed outdoors. Thus, it could be interesting to identify the minimum flow of supplementary oxygen required to prevent AMS. The main goal of this study was to test the hypothesis that administration of low-flow oxygen will improve physical performance in subjects who have not been acclimatized to altitude. To this end, we collected data from a $2-\mathrm{km}$ walk test conducted at high altitude $(5050 \mathrm{~m})$ with 2 levels of supplementary oxygen administration in healthy young male and female subjects. A walk test was chosen since walking is one of the most basic human activities and is absolutely necessary in order to carry out many habitual everyday tasks. Our results provide suggestions for optimization of functional capacity and reduction of AMS symptoms in individuals carrying out submaximal exercise tasks at altitude.

\section{Materials and Methods}

\section{SUBJECTS}

Eleven young women and 16 young men were initially selected from kinesiology students at the University of Antofagasta. All subjects were voluntary participants in the study and were sea-level residents with no prior exposure to
Table 1. Anthropometric data of the study participants (mean \pm standard deviation)

\begin{tabular}{lcc}
\hline & Males & Females \\
\hline $\mathrm{n}$ & 15 & 8 \\
Age (years) & $21.9 \pm 2.0$ & $20.4 \pm 0.5$ \\
Weight $(\mathrm{kg})$ & $73.5 \pm 15.2$ & $58.6 \pm 5.8$ \\
Height $(\mathrm{cm})$ & $172.9 \pm 5.0$ & $161.1 \pm 6.3$ \\
BSA $\left(\mathrm{m}^{2}\right)$ & $1.9 \pm 0.20$ & $1.6 \pm 0.10$ \\
BMI $\left(\mathrm{kg} / \mathrm{m}^{2}\right)$ & $24.5 \pm 4.3$ & $22.6 \pm 1.9$ \\
\hline
\end{tabular}

BSA, body surface area; BMI, body mass index.

altitude within the previous 6 months. None of the subjects had a medical history of pathology or had experienced a previous episode of altitude sickness. One man and 3 women were later excluded from the study following their inability to finish at least one of the walking tests at $5050 \mathrm{~m}$. Table 1 shows the anthropometric characteristics of the experimental subjects used to obtain the data. The participants gave their informed consent to participate in the study following attendance at an information session provided at the beginning of the study, in accordance with the recommendations of the Declaration of Helsinki.

\section{PROCEDURE}

The study participants performed a 2-km walk test in accordance with Oja et $\mathrm{al}^{6}{ }^{6}$ The test was carried out on a 100-m long, flat track delineated by a row of cones marking 10 U-turns. Each subject performed 3 walk tests. Before beginning, and while still located at the starting point, they were given the following simple instructions: "Walk at a regular pace, as fast as you can, but without running." Following these instructions, exercise intensity was sufficient to reach around $80 \%$ of their heart rate reserve. The estimated percentage of heart rate reserve (\%HRR) was calculated according to the formula proposed by Strath et $\mathrm{al}^{7}$ and this value was used to evaluate the extent of individual accomplishment in the $2-\mathrm{km}$ walk test.

The first 2-km walk test (Walk 1) was performed at sea level on the grounds of the University of Antofagasta, and participants subsequently performed 2 more tests at Chajnantor $(5050 \mathrm{~m})$ according to the following experimental protocol: Subjects were randomly assigned to 2 groups with different levels of oxygen administration. One group of individuals received supplementary oxygen at a rate of 1 $\mathrm{L} \mathrm{O}_{2} \cdot \mathrm{min}^{-1}$, and the other group received $3 \mathrm{~L} \mathrm{O}_{2} \cdot \mathrm{min}^{-1}$. Eight men and 4 women were administered $1 \mathrm{~L} \mathrm{O}_{2} \cdot \mathrm{min}^{-1}$, forming the groups $\mathrm{M} 1 \mathrm{~L}$ and $\mathrm{W} 1 \mathrm{~L}$, and 7 men and 4 women were administered $3 \mathrm{~L} \mathrm{O}_{2} \cdot \mathrm{min}^{-1}$, forming the groups M3L and W3L, respectively. Supplementary oxygen was administered via a Campbell face mask connected 
by an adjustable ( 0.5 to $15 \mathrm{~L}$ per minute) regulator valve to a conventional $100 \%$ oxygen cylinder that was attached to a knapsack carried on the subject's back. The entire supplementary oxygen system weighed a total of $4 \mathrm{~kg}$. The first 2-km walk at $5050 \mathrm{~m}$ (Walk 2) was performed carrying the supplementary oxygen system but without oxygen administration. The second 2-km walk at $5050 \mathrm{~m}$ (Walk 3) was performed on the following day carrying the system and breathing the supplementary oxygen. Prior to walk tests, the subjects were administered $\mathrm{O}_{2}$-supplemented air for 10 minutes. All 3 walks were conducted carrying a knapsack on the back, which weighed the same as the medical oxygen cylinder used in Walk 3. In order to avoid a placebo effect between the 2 levels of $\mathrm{O}_{2}$ supplementation, the participants did not know whether they were being supplemented with 1 or $3 \mathrm{~L} \mathrm{O}_{2} \cdot \mathrm{min}^{-1}$. Evaluation of the tests was conducted in 3 groups of 5 participants and 2 groups of 6 participants on the same day, by 6 evaluators carrying 6 knapsacks with oxygen. Since we had only 3 oximeters, it was not possible to take $\mathrm{SpO}_{2}$ measurements during the walk.

Altitude equivalents for the 2 studied conditions can be estimated by applying Dalton's law (partial pressure $=$ total absolute pressure $\times$ volume fraction of gas component) to calculate the inspired partial pressure of oxygen $\left(\mathrm{PiO}_{2}\right)$. However, a $4 \%$ increase in the fraction of inspired oxygen $\left(\mathrm{FiO}_{2}\right)$ can be added per liter of oxygen delivered in 1 minute. Consequently, $1 \mathrm{~L} \mathrm{O}_{2} \cdot \mathrm{min}^{-1}\left(0.25 \mathrm{FiO}_{2} ; \mathrm{PiO}_{2}\right.$ about $85 \mathrm{mmHg}$ ) was equivalent to $4500 \mathrm{~m}$, and $3 \mathrm{~L}$ $\mathrm{O}_{2} \cdot \min ^{-1}\left(0.33 \mathrm{FiO}_{2} ; \mathrm{PiO}_{2}\right.$ approximately $\left.110 \mathrm{mmHg}\right)$ was equivalent to $2500 \mathrm{~m}$.

The walk test environmental conditions differed. At sea level in Antofagasta, an air temperature of $18^{\circ} \mathrm{C}$, $50 \%$ of air relative humidity, $14.7 \mathrm{~km} \cdot \mathrm{h}^{-1}$ of wind speed, and a barometric pressure of 101 kilopascals $(\mathrm{kPa})$ were registered, whereas at Chajnantor these parameters were $1.1^{\circ} \mathrm{C}, 11 \%, 42 \mathrm{~km} \cdot \mathrm{h}^{-1}$, and $55 \mathrm{kPa}$, respectively.

\section{PARAMETERS STUDIED}

Walking time was recorded and the estimated \%HRR was used to quantify the effects of oxygen supplementation. Heart rate at rest (HRrest) and heart rate at end (HRend) were recorded with a cardiac monitor (Polar S810i, Kempele, Finland). Peripheral oxygen saturation $\left(\mathrm{SpO}_{2}\right)$ was measured using a pulse oximeter (Oxypleth 520A, Novametrix Medical Systems Inc, Wallingford, CT USA) before and after the walking tests. Subjective perception of exertion was recorded according to the Ratings of Perceived Exertion (RPE) (6-20 points) from the Borg RPE Scale. Finally, the Lake Louise AMS score was recorded before and after the walk tests at high altitude, as a key indicator of the effects of administering supplementary oxygen. ${ }^{8}$

\section{ASCENT PROTOCOL}

Participants were first required to pass a medical examination in Antofagasta (sea level). Prior to the ascent to Chajnantor plateau, all the subjects were transferred by bus from Antofagasta to San Pedro de Atacama, at 2400 m, where they spent the first night. The following morning, the research team and experimental subjects traveled by bus to the European Southern Observatory base camp facilities (2900 m), where all subjects were checked for AMS symptoms and authorization was obtained for subsequent ascent to the Chajnantor ALMA site $(5050 \mathrm{~m})$. Criteria were established in order to exclude any subject presenting with arterial pressure values greater than 160/100, arterial saturation lower than $90 \%$, or any symptoms of acute respiratory pathology or AMS. Results for all participants were within the normal range. The journey from San Pedro de Atacama to the ALMA site took about 90 minutes. Walk 2 (without a supplementary oxygen supply) was performed less than 3 hours after arrival. The subjects then returned to San Pedro de Atacama to rest and to spend a second night. The same schedule was followed on the third day, but the walk test at high altitude (Walk 3) was performed with a supplementary oxygen supply.

\section{STATISTICS}

Comparisons between the 3 walks for each parameter (Tables 2 and 3) were performed by means of a one-way repeated measures analysis of variance (ANOVA) with 1 factor and 3 levels. For each ANOVA test, the parameter being compared was considered the factor, and the 3 walks (Walk 1, Walk 2, and Walk 3) were the 3 levels. Where ANOVA revealed significant differences, a multiple comparison test using the Holm-Sidak procedure was run post hoc to determine the differences between each pair of walks. In order to avoid confusion, significant differences in the Tables are indicated at $P<.05$. However, it is indicated in the text where the level of significance was greater than $P<.05(P<.01$ or $P<.001)$. Comparisons between before and after for $\mathrm{SpO}_{2}$, as shown in Table 2, Walk 1-to-Walk 2 vs Walk 1-toWalk 3 for walking time (Figure), and the Borg RPE scale (Table 3 ), were conducted by running a paired $t$ test. Comparisons between men and women were conducted using an unpaired $t$ test. The level of significance for all $t$ tests is indicated in the text, with a minimum confidence level of $P<.05$. All statistical tests were performed using SigmaStat 3.1 software (Systat Software, San Jose, California, USA). 
Table 2. Functional parameters after the $2-\mathrm{km}$ walk tests

\begin{tabular}{|c|c|c|c|c|c|c|}
\hline \multirow[b]{2}{*}{ Women } & \multicolumn{2}{|c|}{ Walk 1} & \multicolumn{2}{|c|}{ Walk 2} & \multicolumn{2}{|c|}{ Walk 3} \\
\hline & $W 1 L$ & $W 3 L$ & $W 1 L$ & $W 3 L$ & $W 1 L$ & $W 3 L$ \\
\hline Walking time (min) & $18.8 \pm 0.6$ & $18.1 \pm 0.9$ & $24.0 \pm 1.1^{a}$ & $25.4 \pm 0.6^{a}$ & $22.1 \pm 1.1^{a, b}$ & $24.6 \pm 0.5^{a}$ \\
\hline HR rest (beats $\cdot \min ^{-1}$ ) & $64 \pm 3.6$ & $69 \pm 3.5$ & $101 \pm 7.9^{a}$ & $99 \pm 2.9^{a}$ & $83 \pm 3.6^{a, b}$ & $79 \pm 3.0^{b}$ \\
\hline $\mathrm{HR}$ end (beats $\cdot \min ^{-1}$ ) & $175 \pm 5.1$ & $174 \pm 6.7$ & $174 \pm 5.4$ & $169 \pm 5.4$ & $177 \pm 5.0$ & $174 \pm 2.5$ \\
\hline HRR (\%) & $82.1 \pm 3.5$ & $80.2 \pm 5.0$ & $81.4 \pm 4.2$ & $76.8 \pm 3.6$ & $83.0 \pm 3.9$ & $80.9 \pm 1.7$ \\
\hline $\mathrm{SpO}_{2}$ before walk $(\%)$ & $98.3 \pm 0.3$ & $97.7 \pm 0.3$ & $76.8 \pm 4.0^{a}$ & $81.0 \pm 3.1^{a}$ & $87.7 \pm 0.7^{a, b}$ & $94.1 \pm 0.2^{b}$ \\
\hline $\mathrm{SpO}_{2}$ after walk (\%) & $97.3 \pm 0.3$ & $96.3 \pm 0.3$ & $79.3 \pm 1.0^{a}$ & $77.7 \pm 1.8^{a}$ & $84.7 \pm 0.7^{a, b}$ & $95.5 \pm 0.3^{b}$ \\
\hline Men & $M 1 L$ & $M 3 L$ & $M 1 L$ & $M 3 L$ & $M 1 L$ & $M 3 L$ \\
\hline Walking time (min) & $16.2 \pm 0.6$ & $16.8 \pm 0.6$ & $21.9 \pm 0.5^{a}$ & $24.7 \pm 1.9^{a}$ & $19.2 \pm 0.6^{a, b}$ & $20.2 \pm 0.8^{a, b}$ \\
\hline HR rest (beats $\cdot \min ^{-1}$ ) & $60 \pm 1.4$ & $59 \pm 2.3$ & $87 \pm 4.2^{a}$ & $98 \pm 4.6^{a}$ & $71 \pm 2.1^{a, b}$ & $77 \pm 7.4^{a, b}$ \\
\hline $\mathrm{HR}$ end (beats $\cdot \min ^{-1}$ ) & $177 \pm 3.7$ & $179 \pm 2.9$ & $172 \pm 3.2$ & $170 \pm 3.1$ & $173 \pm 2.4$ & $173 \pm 3.2$ \\
\hline $\operatorname{HRR}(\%)$ & $84.6 \pm 2.7$ & $86.8 \pm 2.1$ & $81.1 \pm 2.4$ & $79.9 \pm 2.1$ & $81.3 \pm 1.9$ & $82.4 \pm 2.0$ \\
\hline $\mathrm{SpO}_{2}$ before walk $(\%)$ & $97.7 \pm 0.2$ & $97.7 \pm 0.2$ & $78.9 \pm 1.8^{a}$ & $72.8 \pm 4.2^{a}$ & $81.6 \pm 1.3^{a}$ & $86.1 \pm 2.9^{a, b}$ \\
\hline $\mathrm{SpO}_{2}$ after walk $(\%)$ & $97.3 \pm 0.2$ & $97.0 \pm 0.5$ & $72.6 \pm 1.3^{a, *}$ & $71.7 \pm 1.6^{a}$ & $80.6 \pm 1.2^{a, b}$ & $85.7 \pm 2.9^{a, b}$ \\
\hline
\end{tabular}

Data are mean values \pm SEM. M, men; W, women; $1 \mathrm{~L}$ and $3 \mathrm{~L}$, supplemented with $1 \mathrm{~L} \mathrm{O}_{2} \cdot \min ^{-1}$ and $3 \mathrm{~L} \mathrm{O}_{2} \cdot$ min $^{-1}$, respectively.

Significant differences $(\mathrm{P}<0.05)$ indicated as:

${ }^{a}$ versus Walk 1 .

${ }^{b}$ versus Walk 2 .

* before vs after a 2 -km walk test.

\section{Results}

Walking times, heart rates, and arterial oxygen saturation before and after the 2-km walk tests are shown in Table 2 . All groups showed significantly longer times in the walk tests at high altitude (Walks 2 and 3) compared to the sea level test (Walk 1). However, for men supplemented with either 1 or $3 \mathrm{~L} \mathrm{O}_{2} \cdot \mathrm{min}^{-1}$ and for women supplemented with
$1 \mathrm{~L} \mathrm{O}_{2} \cdot \mathrm{min}^{-1}$, the duration of the test (Walk 3) was significantly reduced with respect to the test without supplementation (Walk 2). Moreover, if the percentage increases in walking time (with respect to Walk 1 ) are calculated (Figure 1), a significantly lower increase is observed in Walk 3 compared with Walk 2 for M1L, M3L, and W1L groups, although no differences were found for W3L. Supplemen-

Table 3. Borg Ratings of Perceived Exertion (RPE) and Lake Louise AMS scores after the three 2-km walk tests

\begin{tabular}{|c|c|c|c|c|c|c|}
\hline \multirow[b]{2}{*}{ Women } & \multicolumn{2}{|c|}{ Walk 1} & \multicolumn{2}{|c|}{ Walk 2} & \multicolumn{2}{|c|}{ Walk 3} \\
\hline & $W 1 L$ & $W 3 L$ & $W 1 L$ & $W 3 L$ & $W 1 L$ & $W 3 L$ \\
\hline Borg RPE Scale & $12.0 \pm 0.6$ & $13.0 \pm 0.8$ & $15.0 \pm 1.4$ & $17.0 \pm 0.8^{a}$ & $14.0 \pm 1.0$ & $14.5 \pm 1.0^{b}$ \\
\hline Lake Louise Score before walk & - & - & $0.5 \pm 0.3$ & $1.5 \pm 0.6$ & $0.8 \pm 0.3$ & $0.5 \pm 0.3$ \\
\hline Lake Louise Score after walk & - & - & $1.8 \pm 0.9$ & $3.3 \pm 0.6^{c}$ & $1.8 \pm 0.5$ & $2.8 \pm 0.3^{c}$ \\
\hline Men & $M 1 L$ & $M 3 L$ & $M 1 L$ & $M 3 L$ & $M 1 L$ & $M 3 L$ \\
\hline Borg RPE Scale & $13.8 \pm 0.6$ & $14.7 \pm 0.8$ & $15.5 \pm 0.5$ & $16.7 \pm 0.6^{a}$ & $15.3 \pm 0.7$ & $16.7 \pm 0.8^{a}$ \\
\hline Lake Louise Score before walk & - & - & $1.8 \pm 0.2$ & $2.0 \pm 0.6$ & $0.1 \pm 0.1^{b}$ & $1.0 \pm 0.4$ \\
\hline Lake Louise Score after walk & - & - & $5.3 \pm 0.7^{c}$ & $5.2 \pm 1.0^{c}$ & $3.0 \pm 0.7^{b, c}$ & $2.5 \pm 0.8^{b, c}$ \\
\hline
\end{tabular}

Data are mean values \pm SEM. M, men; W, women; $1 \mathrm{~L}$ and $3 \mathrm{~L}$, supplemented with $1 \mathrm{~L} \mathrm{O}_{2} \cdot \mathrm{min}^{-1}$ and $3 \mathrm{~L} \mathrm{O}_{2} \cdot \mathrm{min}^{-1}$, respectively.

Significant differences $(P<.05)$ indicated as:

${ }^{a}$ vs Walk 1.

${ }^{b}$ vs Walk 2.

${ }^{c}$ before vs after a $2-\mathrm{km}$ walk test. 


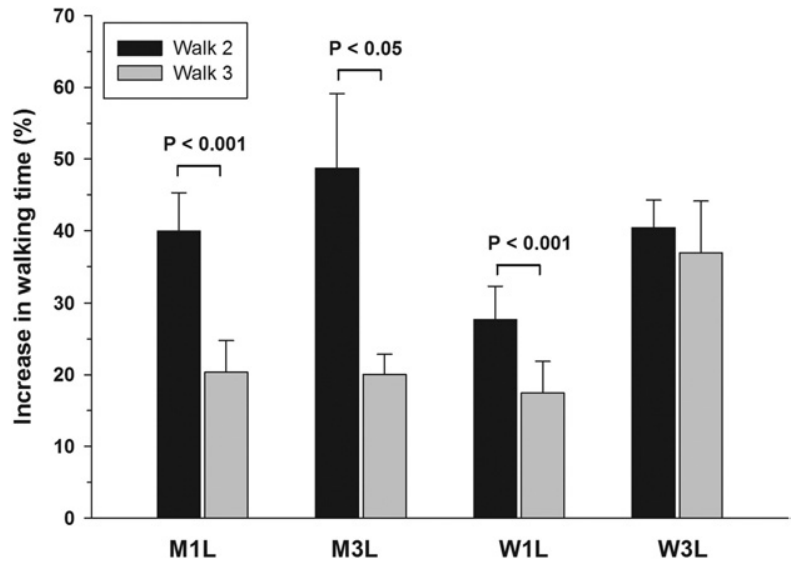

Figure. Increase in walking times on the Chajnantor plateau $(5050 \mathrm{~m})$ after the $2-\mathrm{km}$ tests. Data are mean values \pm SEM. M, men; W, women; $1 \mathrm{~L}$ and $3 \mathrm{~L}$, supplemented with $1 \mathrm{~L} \mathrm{O}_{2} \cdot \min ^{-1}$ and $3 \mathrm{~L}$ $\mathrm{O}_{2} \cdot \min ^{-1}$, respectively.

tary oxygen markedly increased $\mathrm{SpO}_{2}$, and this effect was more noticeable in women than in men (Table 2). As expected, supplementation with $3 \mathrm{~L} \mathrm{O}_{2} \cdot \mathrm{min}^{-1}$ (groups $\mathrm{M} 3 \mathrm{~L}$ and $\mathrm{W} 3 \mathrm{~L}$ ) led to a higher increase in $\mathrm{SpO}_{2}$ than in groups supplemented with $1 \mathrm{~L} \mathrm{O} \mathrm{O}_{2} \cdot \mathrm{min}^{-1}$ (M1L and W1L) and approached $\mathrm{SpO}_{2}$ values recorded at sea level.

From Table 2, it is interesting to note that the time taken to complete the walk test differed significantly between the groups supplemented with $3 \mathrm{~L} \mathrm{O}_{2} \cdot \mathrm{min}^{-1}$ and the groups supplemented with $1 \mathrm{~L} \mathrm{O}_{2} \cdot \mathrm{min}^{-1}$, for both men and women. The heart rate at rest at high altitude was significantly higher than that at sea level, but heart rate recorded at the end of the altitude walks was similar to that recorded at sea level. Since \%HRR is calculated using individual $\mathrm{HR}_{\text {rest }}$ as the reference, this percentage did not differ between the altitude and sea level walks, thus demonstrating the same degree of cardiovascular compromise under both conditions. On the other hand, oxygen supplementation significantly reduced $\mathrm{HR}_{\text {rest }}$ with respect to the nonsupplemented condition and approached the $\mathrm{HR}_{\text {rest }}$ measured at sea level, both in men and women (Table 2).

Table 3 shows the rate of perceived exertion (Borg ratings) and Lake Louise scores. The perception of exertion was higher for exercise at altitude, although this was only significant in some groups. It is worth noting that the W3L group showed a significantly lower perception of exertion in Walk 3 (supplemented) than in Walk 2 (not supplemented), with a significant reduction $(P<.05)$ from $32 \%$ to $12 \%$ in perceived effort intensity over sea level. The Lake Louise scores were significantly higher after most of the walk tests, but to a lesser extentespecially after the test-in practically all the oxygen-supplemented groups, with significant reductions in men but not in women, who had lower scores compared to men when not supplemented.

In order to analyze gender differences, data on walking times, Borg RPE, and Lake Louise scores were compared between men and women. When running the unpaired $t$ tests, it was only necessary to distinguish between $\mathrm{O}_{2}$ supplementation groups $\left(1 \mathrm{~L} \mathrm{O}_{2} \cdot \mathrm{min}^{-1}\right.$ and $\left.3 \mathrm{~L} \mathrm{O}_{2} \cdot \mathrm{min}^{-1}\right)$ for Walk 3, since Walk 1 and Walk 2 were performed without $\mathrm{O}_{2}$ supplementation. After grouping the data for W1L-W3L and M1L-M3L in Walks 1 and 2 from Tables 2 and 3, men showed significantly lower walking times than women (16.6 vs $18.5 \mathrm{~min}, P<.01$ ) but higher perceived exertion (14.1 vs $12.5, P<.05$ ) when the $2-\mathrm{km}$ walk test was performed at sea level (Walk 1). However, at high altitude and without supplementation (Walk 2), this difference disappeared, showing walking times of $23.7 \mathrm{~min}$ for men and $24.7 \mathrm{~min}$ for women and an identical 16.0 score for Borg RPE. Interestingly, after Walk 2, women showed significantly higher $\mathrm{SpO}_{2}(78.6 \%$ vs $72.2 \%, P<.001)$ and lower Lake Louise scores ( 2.5 vs 5.2, $P<.01$ ). With $\mathrm{O}_{2}$ supplementation (Walk 3), the walking time in men was again lower than that recorded for women (Table 2) both after 1 $\mathrm{L} \mathrm{O}_{2} \cdot \min ^{-1}(P=.062)$ and after $3 \mathrm{~L} \mathrm{O}_{2} \cdot \min ^{-1}(P<.01)$ although $\mathrm{SpO}_{2}$ in women was higher than in men, both before and after the test (Table 2).

\section{Discussion}

\section{INDIVIDUAL DIFFERENCES BETWEEN THE 3 WALK TESTS}

From Table 2, it is evident that both the men and the women took significantly longer to perform the $2-\mathrm{km}$ walk at altitude. Similar results were obtained in a preliminary study ${ }^{3}$ at the same location, with time delays at altitude ranging from $35 \%$ in men $(n=7)$ to $46 \%$ in women $(n=7)$ and cardiovascular loads of $84.9 \%$ and $83.8 \%$, respectively. For the present study, we added a group of individuals who were supplemented with 1 or $3 \mathrm{~L} \mathrm{O}_{2} \cdot \mathrm{min}^{-1}$. Oxygen administration led to better physical performance during the walk test, although the walking times after oxygen supplementation were still significantly longer than those obtained during normoxia (Table 2 and Figure). It is interesting to note that, in order to significantly reduce the walking times during hypoxia, it was sufficient to use only $1 \mathrm{~L} \mathrm{O}_{2} \cdot \mathrm{min}^{-1}$ supplementation. This finding could have important practical implications in terms of economic costs, since $\mathrm{O}_{2}$ expenditure by workers could be significantly reduced.

During acute hypoxia, exercise capacity is reduced as the $\mathrm{O}_{2}$ tension of the inspired air falls, due to a reduction in arterial oxygen content as a consequence of oxygen desaturation. Acute hypoxia places oxygen diffusion limitations on the lungs, leading to a reduction in inspired 
oxygen tension that is especially problematic during exercise, when oxygen consumption increases. For this reason, higher values of $\mathrm{SpO}_{2}$ for both 1 and $3 \mathrm{~L}$ $\mathrm{O}_{2} \cdot \mathrm{min}^{-1}$ supplementation before and after Walk 3, compared to before and after Walk 2, could explain the significantly lower walking times observed after oxygen supplementation was administered (Table 2).

Several reasons could explain the loss of muscle work capacity during Walk 2 compared with Walk 1 and Walk 3. Early studies indicated that reductions in lung diffusion and cardiac output and the high cost of ventilation are limiting factors in exercise at altitude. More recently, Calbet et $\mathrm{al}^{9}$ studied humans exercising at a submaximal level in normobaric hypoxic conditions that simulated an altitude of $5300 \mathrm{~m}$ and found that, as a consequence of reduced arterial oxygen content, leg oxygen delivery fell with hypoxia by $25 \%$. Lastly, research on acute exposure of unacclimatized humans to simulated, acute, severe, and short-term hypobaric hypoxia (4 hours at $5500 \mathrm{~m}$ ) has indicated that a notable decrease in $\mathrm{SpO}_{2}$ significantly modifies the plasma levels of oxidative stress indicators. ${ }^{10}$ These authors reported significant increases in the percentage of oxidized glutathione with respect to the total plasma glutathione content, high levels of lipid peroxidation and protein oxidation, and a decrease in plasma total antioxidant status. Since polyunsaturated fatty acids are susceptible to increased oxidant production, all these changes could affect the functionality of circulating blood cells and their capacity to transport oxygen to the tissues by peroxidative modification of their membrane lipids. Thus, both a reduction in oxygen delivery to working muscles and/or muscle damage induced by oxidative stress could explain the differences found for walking times in the three 2-km walk tests (Table 2).

Our results show a marked increase in the severity of AMS after the 2-km walk, and this increase was significant in almost all groups (Table 3). This finding is in accordance with Roach et $\mathrm{al}^{11}$ who reported a pronounced worsening of AMS with submaximal exercise at a simulated altitude of $4800 \mathrm{~m}$ in a hypobaric chamber. They concluded that an $8 \%$ reduction in $\mathrm{SpO}_{2}$ during exercise could be one of the main determinants of the exacerbation of AMS signs. We measured $\mathrm{SpO}_{2}$ at the end of the walking tests and found significant differences between oxygen-supplemented and nonsupplemented walks (Table 2). Thus, our results suggest that more severe hypoxemia during the performance of the test could be responsible for increased AMS scores. Moreover, it is interesting to note that men, but not women, presented significantly lower AMS scores when they were oxygen-supplemented, which could be due to the differences found in $\mathrm{SpO}_{2}$ at the beginning of the test, providing support for the relationship between low arterial oxygen saturation and the subsequent development of AMS. ${ }^{8}$

\section{GENDER DIFFERENCES}

An interesting finding in this study concerned the gender differences found in some of the parameters studied. Men presented significantly shorter walking times but higher RPE rates at sea level. However, this trend changed in Walk 2 in which no differences either in walking time or RPE rates were found between men and women. Interestingly, a significant difference in $\mathrm{SpO}_{2}$ after the walking test was found after Walk 2, meaning that a lower hypoxemia level could be responsible for the reduction of walking time differences between men and women and RPE rates in Walk 2. This difference in $\mathrm{SpO}_{2}$ is consistent with previous findings. ${ }^{12}$

After Walk 3, women again presented longer walking times and lower RPE rates, although this latter was not significant. When the percentage of RPE reduction with respect to sea level values was calculated, group W3L showed significantly lower perception of exertion in Walk 3 than in Walk 2 (from $32 \%$ to $12 \%, P<.05$ ). In other words, these women were delayed by a similar time in the altitude walk test with supplemental oxygen, but their perception of exertion was significantly lower. In addition, higher $\mathrm{SpO}_{2}$ values were observed in women than in men both before and after Walk 3 (Table 2). These findings may indicate that hypoxia affects women to a lesser extent.

A lower Borg's score in women was in accordance with the longer test time, higher arterial oxygen saturation, and lower AMS severity after the walking test compared with the men. Nevertheless, the end-test heart rate and heart rate reserve were similar for both genders, thus indicating a similar level of achievement during the walking test for all subjects. Surprisingly, the lower physical performance profile of women compared to men seems to be AMS-protective at high altitude, at least under the severe conditions of the present study, as can be deduced from the significantly lower Lake Louise scores for women compared to men. Consequently, whereas oxygen administration clearly reduced AMS symptoms in men, this effect was not as marked in the women. These findings also correlate with the lower RPE rates found in women.

\section{STUDY LIMITATIONS AND FUTURE APPLICATIONS}

Insurmountable logistical constraints imposed some limitations on the present study. Arterial saturation measurements were not performed immediately after the walk test, since about 2 minutes were required to collect these data inside an ambulance, where the fingertips were much better perfused. Supplemental oxygen administration was only possible on the second day instead of on a randomized basis between the 
2 ascents, thus the possibility of a small acclimatization effect must be considered alongside the supplementary oxygen effect in the measurements performed during the test on the second day. However, it is reasonable to believe that this effect would have been very small, as only one night was spent at San Pedro de Atacama $(2400 \mathrm{~m})$ and, likewise, it is well-known that AMS scores are higher in the second day after altitude arrival. ${ }^{13}$ Lastly, since the participants were aware when they were receiving supplemental oxygen, a placebo effect cannot be ruled out between Walk 2 and Walk 3. An interesting finding of the present study concerned the gender difference revealed when undertaking a similar physical challenge, and the apparently lower effectiveness of supplementary oxygen supply in women. These aspects will need to be considered in the future, given the increasing trend towards incorporation of women into the labor force in social environments where high altitude activities are performed. Oxygen supplementation has been postulated as a feasible method for improving both physical and mental efficiency when working at high altitude. ${ }^{5}$ Such a strategy is particularly useful given that complete acclimatization is not possible for many altitude workers, who are usually obliged to undergo short periods of altitude exposure and a very fast ascent and descent. Under these time and geographical constraints, complete and effective acclimatization through adaptive physiological response is impossible, regardless of individual altitude tolerance. However, supplementary oxygen administrationeven at moderate delivery rates, as shown in the present study-can noticeably improve physical capacity, perceived exertion, and AMS symptoms that, in turn, could result in more comfortable and safer task accomplishment.

\section{Acknowledgments}

The authors are grateful to Chiledeportes (II Región) for their sponsorship of research projects in the area of Altitude Physiology and Medicine through the Sports Sciences Category, to the ALMA (Atacama Large Millimeter Array) and ESO (European Southern Observatory) authorities for their support of the present study, and especially to Jacques Lassalle, Daniel Sosa, and Raul Aguilar for their kind collaboration. This study was funded in part through the Agencia Espa- ñola de Cooperación Internacional para el Desarrollo (AECID) project A/025717/09 and the Chiledeportes project in the Sports Sciences Category (Resolución de convenio \#745).

\section{References}

1. Sutton JR, Coates G, Houston CS. The Lake Louise Consensus on the Definition and Quantification of Altitude Illness. Burlington, VT: Queen City Printers; 1992.

2. Di Prampero PE. Factors limiting maximal performance in humans. Eur J Appl Physiol. 2003;90:420-429.

3. Silva Urra J, Aliaga P, Carvajal X, et al. El desafío de caminar a $5.050 \mathrm{~m}$ de altitud en el llano de Chajnantor. Cienc Trab. 2005;7:49-55.

4. West JB. Commuting to high altitude: value of oxygen enrichment of room air. High Alt Med Biol. 2002;3: 223-235.

5. West JB. Improving oxygenation at high altitude: acclimatization and $\mathrm{O}_{2}$ enrichment. High Alt Med Biol. 2003;4: 389-398.

6. Oja P, Laukkanen R, Pasanen M, Tyry T, Vuori I. A 2-km walking test for assessing the cardiorespiratory fitness of healthy adults. Int J Sports Med. 1991;12: 356-362.

7. Strath SJ, Swartz AM, Bassett DR Jr, O'Brien WL, King GA, Ainsworth BE. Evaluation of heart rate as a method for assessing moderate intensity physical activity. Med Sci Sports Exerc. 2000;32(Supp19):S465-70.

8. Roach RC, Greene ER, Schoene RB, Hackett PH. Arterial oxygen saturation for prediction of acute mountain sickness. Aviat Space Environ Med. 1998;69:11821185.

9. Calbet JAL, Boushel R, Radegran G, Sondergaard H, Wagner PD, Saltin B. Determinants of maximal oxygen uptake in severe acute hypoxia. Am J Physiol Regul Integr Compe Physiol. 2003;284:R291-303.

10. Magalhaes J, Ascensao A, Viscor G, et al. Oxidative stress in humans during and after 4 hours of hypoxia at a simulated altitude of 5500 m. Aviat Space Environ Med. 2004;75:16-22.

11. Roach RC, Maes D, Sandoval D, et al. Exercise exacerbates acute mountain sickness at simulated high altitude. J Appl Physiol. 2000;88:581-585.

12. Ricart A, Pagès T, Viscor G, Leal C, Ventura JL. Sexlinked differences in pulse oxymetry. $\mathrm{Br} J$ Sports Med. 2008;42:620-621.

13. Richalet JP, Donoso MV, Jimenez D, et al. Chilean miners commuting from sea level to $4500 \mathrm{~m}$ : a prospective study. High Alt Med Biol. 2002;3:159-166. 